\title{
Desafiando a mitologia dos BRICS
}

\author{
Rosemary GaLLI \\ Patrick Bond; Ana Garcia, BRICS: an Anti-Capitalist \\ CRitioue, London, Pluto Press, 2015.
}

Patrick Bond e Ana Garcia reúnem, na coletânea por eles editada BRICS: an Anti-Capitalist Critique, um formidável conjunto de pesquisas acadêmicas que buscam analisar as frequentemente contraditórias posições coletivas e individuais dos países conhecidos como BRICS: Brasil, Rússia, Índia, China e África do Sul. O objetivo é averiguar se as ações das assim chamadas economias emergentes representam um desafio à atual hierarquia da ordem capitalista internacional ou se simplesmente contribuem para incorporá-los a dita hierarquia.

Na Introdução do livro, Bond e Garcia delineiam quatro grandes perspectivas (subdividas em dez variações) sobre o fenômeno dos BRICS e distinguem quatro categorias ou classes de pessoas que sustentam tais visões. Esta categorização fornece uma ferramenta valiosíssima - um ponto de partida útil - para professores, estudantes e público interessado em identificar os vieses na crescente literatura acadêmica e nas reportagens jornalísticas sobre o assunto. A posição "BRICS pelo Alto", defendida por políticos, estadistas, elites corporativas e similares, incorpora aqueles que caracterizam os BRICS como anti-imperialista, isto é, contrários ao capitalismo imperialista ainda que apenas em um nível retórico; ou como subimperialista, isto é, um parceiro menor dos Estados Unidos, da Europa ou do Japão; ou como interimperialista ao promover os interesses dos membros coletivos ou dominantes em oposição àqueles dos Estados Unidos e seus aliados.

\section{$\overline{\text { Rosemary GaluI }}$}

Doutora em relações Internacionais, pesquisadora e consultora independente 
Acadêmicos, intelectuais e similares assumem uma postura de "BRICS pelo Meio": alguns se aliam aos ativistas do "BRICS de Baixo" em suas críticas, enquanto outros são favoráveis ao bloco, havendo outros ainda que adotam a postura cautelosa de aguardar para ver. O grupo dos "de Baixo", com quem Bond e Garcia simpatizam, é composto por ativistas que se opõem às tendências imperialistas do bloco, no contexto das lutas locais, nacionais ou "internacionais de solidariedade". Claramente, o projeto de Bond e Garcia é apresentar argumentos para fortalecer a última posição. A quarta posição identificada por eles, na literatura, é a "Pró-Ocidental de Negócios", encontrada entre aqueles grupos no interior dos países dos BRICS que veem o bloco como potencial ameaça à ordem internacional estabelecida, com a qual eles se associam.

O livro se divide em três seções: a primeira indaga se os BRICS desempenham um papel subimperial, interimperial ou capital-imperialista na política econômica global. A segunda examina as ações dos BRICS como unidade e as ações de seus membros individuais em países africanos, latino-americanos e asiáticos selecionados, enquanto a terceira seção situa os BRICS dentro dos marcos do capitalismo global.

Analisamos, em seguida, os argumentos apresentados pelos autores do livro. Patrick Bond abre a discussão sobre como caracterizar a posição dos BRICS na economia política global. Ele claramente enxerga as ações coletivas dos BRICS como subimperialismo, citando não apenas a Rui Mauro Marini, que primeiro cunhara o termo, mas também trabalhos de Rosa Luxemburgo e David Harvey para apoiar e expandir a tese de Marini. Tem sido típico de poderes subimperialistas um extrativismo de recursos regionais, exportação de capitais e facilitação de monopólios domésticos. Bond agrega os papéis adicionais de garantir a estabilidade regional e promover o neoliberalismo global em arenas internacionais, tais como a Organização Mundial do Comércio e as Cúpulas Climáticas.

Em seu capítulo, Mathias Luce conduz a impressionante tarefa de sistematizar os trabalhos dispersos de Marini sobre a categoria analítica de subimperialismo. Marini o definira como a forma mais 
avançada de capitalismo dependente, na qual a formação social subimperialista não apenas atua como emissor de mais-valia para o centro imperialista, como também é capaz de se apropriar da mais-valia de países menos desenvolvidos. Desta forma, ele substitui algumas das condições do capitalismo dependente e consegue obter uma autonomia relativa. Marini enfocou-se sobretudo no Brasil e em seu status em desenvolvimento na economia mundial. Ao juntar os diferentes elementos das análises de Marini, Luce consegue estendê-los às economias da África do Sul e Índia. Em sua visão, China e Rússia estão fora do conceito, constituindo-se em polos de tendências imperialistas.

Em sua contribuição, Virginia Fontes enfrenta a questão do meio social em que surge o subimperialismo. Se, como argumenta Luce, o subimperialismo é um desdobramento da escola de pensamento conhecida como Teoria do Desenvolvimento Marxista, então Fontes apresenta ao leitor outro desdobramento teórico semelhante. Ela foca não apenas nas formações sociais nacionais no interior do capitalismo global, mas também no desenvolvimento deste último: especificamente, a expansão capitalista via integração das classes sociais domésticas. Ela denomina esse processo de "capital-imperialismo". Não é um processo histórico ordeiro, já que é impulsionado pelas contradições inerentes ao capitalismo, especialmente na medida em que colide com as aspirações e planos de várias formações sociais nacionais. Além disso, o capital-imperialismo não é simplesmente um processo econômico, mas envolve todas as esferas da existência, ainda que sua essência permaneça sendo o aumento e a apropriação da mais-valia. Fontes, então, descreve três períodos de avanço.

Após a II Guerra Mundial, o capitalismo avançou além da necessidade de controle territorial para um império informal que interconecta os capitalismos nacionais. Nos anos 1960 e 1970, grandes concentrações de capital ocorreram em todos os setores, requerendo subordinação de altos contingentes populacionais enquanto classe trabalhadora. A proliferação de instituições multilaterais transformou as relações interestatais e legitimou a transformação capital-imperialista, considerada como "desenvolvimento". Além disso, o ideal democrático foi promulgado como 
sendo concomitante ao "progresso" econômico e gerou expectativas, demandas e, consequentemente, contradições. Juntamente à internacionalização do capital, veio a internacionalização das lutas sociais, exemplificada pelo Maio de 1968 francês. Desde então, Estados capital-imperialistas têm buscado desativar tal resistência através de cooptação. Finalmente, os modos de reprodução social capital-imperialistas penetraram os Estados anteriormente subalternos que, então, adotaram as mesmas atitudes e estratégias: os BRICS "personificam o mais impressionante ápice de países subalternos elevados... a uma industrialização e generalização de relações sociais capitalistas que requerem uma expansão para fora (p.58) ".

Leo Panitch não discorda de Luce ou Fontes sobre a integração das potências capitalistas no interior do império informal, dentro do qual os Estados Unidos se constituem no Estado imperial dominante. Apesar do apoio dos BRICS às políticas neoliberais do centro, Panitch assegura que eles não estão plenamente integrados ao círculo imperial por não possuir conexões militares e de segurança com os Estados da OTAN. A fim de desarmar o império informal, ele argumenta que as lutas sociais precisam se concentrar em mudar "o balanço de forças de classe no interior dos próprios EUA (p.67) ".

Contrastando com Panitch, Claudio Katz vê o surgimento da China como uma potência global central, conforme demonstrado por seu crescimento econômico fenomenal e seu papel central no apoio ao dólar estadunidense e ao euro, durante a crise de 2008-9, que ameaçou todo o sistema financeiro global. Ao mesmo tempo, desequilíbrios nas taxas de investimento e consumo têm aberto contradições no interior das elites e populações rurais e urbanas chinesas. Ao contrário de Bond, Luce e Panitch, a intenção de Katz em seu capítulo é a de diferenciar a China dos outros Estados integrantes dos BRICS, bem como diferenciar cada um deles dos demais. Ele também inclui a Turquia em suas análises das categorias variadas no interior do capitalismo global.

A abordagem da segunda parte é, sobretudo, empírica e se distingue do método teórico-analítico da primeira parte. A seção abre-se com uma série de pequenos artigos sobre a natureza 
exploradora das corporações dos BRICS, no sul da África, em particular. Essas empresas têm sido, acima de tudo, extrativistas, não apenas como exportadoras de riqueza mineral, mas em virtude de algumas práticas, como transferência de preços e evasão fiscal. Dois dos artigos seguintes examinam corporações brasileiras na África (Garcia e Kato e Marshall) e no Canadá (Marshall). Pedro Henrique Campos descreve e analisa a ascensão de multinacionais brasileiras no setor da construção civil pesada, enquanto Bonilla Martinez foca nas explorações de empresas petrolíferas chinesas, na região andina da América do Sul. Ambos os artigos expõem o alto envolvimento estatal no apoio à sua expansão corporativa e penetração nos países receptores. Campos mostra ainda o quão difundido tem sido este desenvolvimento: companhias brasileiras de construção civil encontraram lucrativos mercados nos Estados Unidos, no Oriente Médio e, acima de tudo, na América Latina e na África. Ele argumenta que a influência dessas empresas sobre as políticas doméstica e internacional garantem à economia brasileira certa autonomia vis-à-vis as posições anteriormente dominantes das corporações transnacionais.

O artigo de Braathen, Mascarenhas e Soederberg sobre lutas sociais no Rio de Janeiro em torno do projeto dos Jogos Olímpicos estaria melhor localizado na terceira parte, junto aos demais artigos do "BRICS de baixo", na medida em que analisa o levante popular contra os planos da prefeitura municipal. Os autores ponderam se essa rebelião multifacetada qualificaria o Rio como "cidade rebelde" nos marcos do pensamento de David Harvey. Também possivelmente deslocados de seu melhor lugar estejam os próximos dois capítulos que enfocam o capitalismo russo e a sua diferenciação das demais economias políticas dos BRICS, bem como a sua localização no contexto do capitalismo global. Utilizando o sistema-mundo como marco, Dzarasov caracteriza o capitalismo russo como um capitalismo semiperiférico dependente, enquanto Pozo vê a Rússia como um poder imperialista neoliberal de características próprias. Pozo descreve sua expansão com a formação da União Econômica Euroasiática, mas também enfatiza as debilidades da Rússia e a natureza contraditória de seu impulso imperialista. De modo similar a Bonilla Martinez e Pozo, 
ele aponta as relações simbióticas entre corporações e o Estado, mas também ressalta a distinção do capitalismo russo em comparação àquele dos outros BRICS. Com sua insistência em um marco teórico-analítico e nos traços distintivos do capitalismo russo, os capítulos de Dzarasov e Pozo possuem mais similaridades com o trabalho de Katz na primeira parte do que com os textos precedentes sobre expansão corporativa e, provavelmente, estariam mais bem localizados ali.

Os primeiros três artigos da terceira parte ressaltam a diferença entre os imperialismos passados e a ordem econômica internacional desde a II Guerra Mundial. Sua preocupação é entender como os BRICS se inseriram e se afirmaram no sistema contemporâneo. O argumento de Robinson é que apenas uma análise político-econômica pode revelar a estratégia subjacente aos desafios que os países dos BRICS, individualmente e em grupo, colocam à ordem econômica internacional. De acordo com ele, esses desafios representam a disputa de suas elites por maior inclusão e influência no interior do capitalismo global. Enquanto, para Robinson, a ordem internacional é estruturalmente composta por corporações transnacionais gigantes, para Elmar Altvater, ela é composta de Estados-nações e relações interestados dominados pelos Estados Unidos, com o apoio da ideologia neoliberal e força militar. Através de áreas de comércio e investimento no Atlântico e Pacífico, ela busca a expansão contínua de suas corporações nacionais e transnacionais. Altvater argumenta que esses acordos de livre comércio contêm o potencial de danos ainda maiores ao desenvolvimento nacional, na medida em que promovem mais o consumo dos recursos limitados do planeta. A estratégia neoliberal é transformar limites naturais em oportunidades de mercado: "a política ambiental se encaixa perfeitamente com o sistema de mercado (p.243)" através de propostas como a Redução de Emissões de Desflorestamento e Degradação (REDD), Pagamento por Serviços de Ecossistema (PES, na sigla em inglês) e assim por diante. Por sua vez, tais projetos legitimam as políticas neo-extrativistas praticadas pelos BRICS e outros. Devido à ampla difusão do neoliberalismo, a visão de Altvater sobre futuras ações globais em relação aos limites do crescimento é pessimista. 
A análise de Moyo e de Yero sobre a economia contemporânea global é mais próxima daquela de Altvater do que da de Robinson, sendo mais equilibrada que a deste último ao reconhecer comportamentos relativamente autônomos entre os países individuais dos BRICS, particularmente a China. Eles citam como exemplos diferenças de participação no que chamam de projeto militar ocidental e também distintos "modos de engajamento (p.249) " na África. Contudo, Moyo e Yero estão fundamentalmente interessados em como um projeto antissistêmico poderia ser promovido de modo similar àquele encarnado na Declaração de Não-Alinhamento de Bandung. Eles sugerem que o caminho adiante envolveria pactos militares regionais que levem a novas formas de integração regional.

Os seguintes oito artigos enfocam-se nos caminhos efetivamente trilhados pelos BRICS, individualmente e como um coletivo. A incorporação dos BRICS ao G20 tem levado à adoção de uma política de inclusão financeira direcionada à oferta de crédito e a outras políticas para os pobres, como meios de aliviar a pobreza. Susanne Soederberg descreve como essa estratégia neoliberal tem deixado os pobres vulneráveis às crises cíclicas dos mercados financeiros, o que, argumenta ela citando a David Harvey, equivale à "acumulação por desapropriação".

O artigo de Ho-fung Hung se foca no papel da China para a manutenção do dólar como principal moeda de reserva internacional. Ele avalia isso como uma estabilização da posição dos Estados Unidos como poder militar e econômico internacional dominante, apesar de seu declínio e do próprio crescimento fenomenal da China. O modelo de desenvolvimento chinês baseado no crescimento induzido por exportações tem deixado o país vulnerável à recessão econômica em seus principais mercados ocidentais.

Reconhecendo visões opostas sobre a trajetória dos BRICS na ordem mundial, Achin Vanaik avalia, em seu curto artigo, a força econômica coletiva do grupo, mas se concentra nas contradições internas subjacentes a esse crescimento e que limitam sua coesão como um grupo coletivo. Isto o torna bastante cético em relação ao potencial reformador dos BRICS. Em uma vívida linguagem não acadêmica, Vijay Prashad descreve o que ele enxerga como frágil 
estado econômico e político do Sul Global em contraste com o dominante G7. Prashad tem esperanças em relação à Alternativa Bolivariana para as Américas (ALBA) e sua proposta de "solidariedade, cooperação, respeito à soberania e desenvolvimento desigual (p.268) ". Ele sustenta que os BRICS deveriam seguir essa rota em vez de buscar inclusão na ordem dominante.

Immanuel Wallerstein vê todo o sistema-mundo em crise. Como exemplo, ele cita o perene declínio na geração de empregos nos últimos 30-40 anos. A instabilidade política é outro fator importante, particularmente diante do declínio do poder estadunidense que tem levado a um mundo multipolar. Wallerstein avalia o papel dos BRICS desde várias perspectivas e conclui que poderia ser apenas um fenômeno passageiro. Reddy concorda com a maioria dos autores da terceira parte no que diz respeito aos esforços coletivos dos BRICS não representarem uma ruptura com o atual sistema. Domesticamente, todos são economias capitalistas perseguindo políticas internas e externas compatíveis com suas elites domésticas. Ele afirma que ainda que seus impressionantes crescimentos, na estrutura política e econômica, sejam augúrio de uma estrutura mundial multipolar, essa ainda será uma estrutura capitalista.

Os coeditores fecham o volume, demonstrando a relevância dos vários posicionamentos sobre os BRICS, delineados na Introdução, particularmente em referência às recentes cúpulas dos BRICS. Longe de serem categorias acadêmicas abstratas, Patrick Bond ilustra sua utilidade para o esclarecimento das realidades políticas da cúpula de 2015, em que os chefes-de-estado do "BRICS pelo Alto" deram os toques finais ao Novo Banco de Desenvolvimento e criaram uma estrutura cívica de organizações do "BRICS pelo Meio" próximas à política governamental. Longe de criar um rival ao FMI e Banco Mundial, os líderes declararam que a estratégia do Novo Banco de Desenvolvimento seria cooperar com eles. Bond mostra como o novo banco reforça as organizações financeiras multilaterais, enquanto o papel da assim chamada Estrutura Cívica seria legitimar, e não questionar, as decisões intergovernamentais. Tanto ele quanto Ana Garcia defendem a necessidade de um movimento "BRICS de Baixo" como única forma de desafiar o 
capitalismo global e tais instituições multilaterais. Ainda que Bond mencione várias questões que têm dado surgimento a movimentos transnacionais, como a Campanha de Justiça Climática, ele reconhece que eles são apenas movimentos de agenda única, quando o que se precisa é de um "internacionalismo da sociedade civil (p.295) ". Garcia aborda as dificuldades de países com histórias e línguas distintas unirem suas instituições governamentais e não-governamentais. Além disso, existem diferenças de visão sobre o papel coletivo dos BRICS, especialmente em referência ao Novo Banco de Desenvolvimento, evidentes já nas cúpulas de representantes da sociedade civil de 2013 e 2014. Contudo, Garcia insiste que uma estratégia social e uma luta comuns precisam ser construídos, a partir das experiências de todos em suas resistências nacionais e internacionais particulares aos excessos capitalistas.

Os coeditores fizeram um notável trabalho ao reunir esse leque de interpretações sobre a economia política internacional e os significados do surgimento dos BRICS, tanto individualmente quanto como grupo. A coesão do livro se manifesta em um consenso geral em descrever o sistema-mundo como uma ordem capitalista global, ainda dominada pelos Estados Unidos/Imperialismo Ocidental, por muito que este possa estar em decadência. Ainda assim, existe muita discussão sobre o que os BRICS realmente representam. Como visto, os coeditores apresentam um argumento para seguir adiante, não apenas na continuação do debate, mas na construção de uma resistência global à estrutura capitalista da economia política mundial. Como tal, o livro poderia ser visto como um manual para ativistas, mas ele é muito mais que isso. Seu apelo alcança uma ampla variedade de estudantes de áreas como relações internacionais, economia internacional, mudança social e estudos do desenvolvimento. Sua riqueza de informações e dados poderia interessar também a uma audiência muito mais ampla.

Se houvesse alguma crítica a fazer, seria à organização interna do volume. Como já mencionado, parece fora de lugar a colocação dos artigos de Dzarasov e Pozo na segunda parte. Possivelmente, juntar esses artigos com o texto de Claudio Katz em uma subseção da primeira parte, ou mesmo em uma nova seção própria, 
melhoraria a coerência do livro. Além disso, o subtítulo do livro é "Uma Crítica Anticapitalista" (An Anti-Capitalist Critique), quando o que se apresenta são várias críticas dessa natureza. Essa certamente foi uma decisão deliberada dos coeditores, mas o leitor não deixará de se perguntar se, além do resumo que oferecem dos vários artigos, sua conclusão não deveria ter se engajado com os vários argumentos apresentados de modo a servir como ponto de partida para que estudantes e ativistas pudessem formar seu próprio pensamento crítico.

Tradução: Clayton M. Cunha Filho. 